\title{
Autosomal Dominant Neurohypophyseal Diabetes Insipidus in Two Families
}

\author{
Molecular Analysis of the Vasopressin-Neurophysin II Gene and Functional Studies of Three \\ Missense Mutations
}

\author{
C.M. Hedrich ${ }^{a}$ A. Zachurzok-Buczynskac A. Gawlik ${ }^{c}$ S. Russ ${ }^{a} \quad$ G. Hahn ${ }^{\text {b }}$ \\ K. Koehler ${ }^{\mathrm{a}} \quad$ E. Malecka-Tenderac ${ }^{\mathrm{c}}$ A. Huebner ${ }^{\mathrm{a}}$ \\ ${ }^{a}$ Children's Hospital and b Department of Pediatric Radiology, Technical University Dresden, Dresden, Germany, \\ and 'Department of Pediatric Endocrinology and Diabetes, Medical University of Silesia, Katowice, Poland
}

\section{Key Words}

Diabetes insipidus • Arginine vasopressin • Neurophysin II • AVP gene

\begin{abstract}
Background: Autosomal dominant familial neurohypophyseal diabetes insipidus (adFNDI) is a rare disease with symptoms of polydipsia, polyuria and dehydration caused by arginine vasopressin deficiency. Disease onset is within infancy or adolescence. A variety of disease-causing mutations of the arginine vasopressin neurophysin II gene (AVP) on chromosome 20p13 have been described. Methods: Two Polish families with adFNDI were screened for mutations. Processing of wild-type (WT) and mutant AVP was monitored using immunocytochemical methods in stably transfected Neuro2A cells. AVP secretion into the cell culture supernatant was investigated with an enzyme immunoassay. Results: In the first family a heterozygous p.G96D mutation was identified. Some patients additionally carried a novel heterozygous mutation p.A159T. The second family presented with a heterozygous mutation p.C98G. Confocal laser microscopy unveiled accumulation of p.G96D and p.C98G prohormones in the cellular bodies, whereas WT and p.A159T prohormones and/or processed products were lo-
\end{abstract}

\section{KARGER}

Fax +41613061234 E-Mail karger@karger.ch www.karger.com
(ㄷ) 2009 S. Karger AG, Basel

0301-0163/09/0712-0111\$26.00/0

Accessible online at:

www.karger.com/hre cated in the tips of cellular processes. Reduced levels of AVP in supernatant culture medium of p.G96D and p.C98G transfected cells in comparison to p.A159T and WT cells were found. Conclusions: We conclude that the p.G96D and p.C98G mutations cause adFNDI in the two reported families. The sequence variant p.A159T does not seem to have disease-causing effects.

Copyright $\odot 2009$ S. Karger AG, Basel

\section{Introduction}

Autosomal dominant familial neurohypophyseal diabetes insipidus (adFNDI) is a rare disease caused by central vasopressin deficiency and seems to be largely, if not completely, penetrant. Commonly, the disease becomes apparent in the first decade of life after a non-suspicious period during infancy. adFNDI typically presents with persistent thirst, polydipsia and polyuria due to a deficiency of circulating arginine vasopressin (AVP) [1]. AVP is usually synthesized by magnocellular neurons of the supraoptic and paraventricular nuclei of the hypothalamus $[1,2]$.

Consistent with the clinical findings, AVP deficiency develops in the first months of life and shows a rapid pro-

Prof. Dr. Angela Huebner, MD, PhD

University Children's Hospital, Technical University Dresden

Fetscherstrasse 74, DE-01307 Dresden (Germany)

Tel +49351458 2926, Fax +493514584334

E-Mail angela.huebner@uniklinikum-dresden.de 


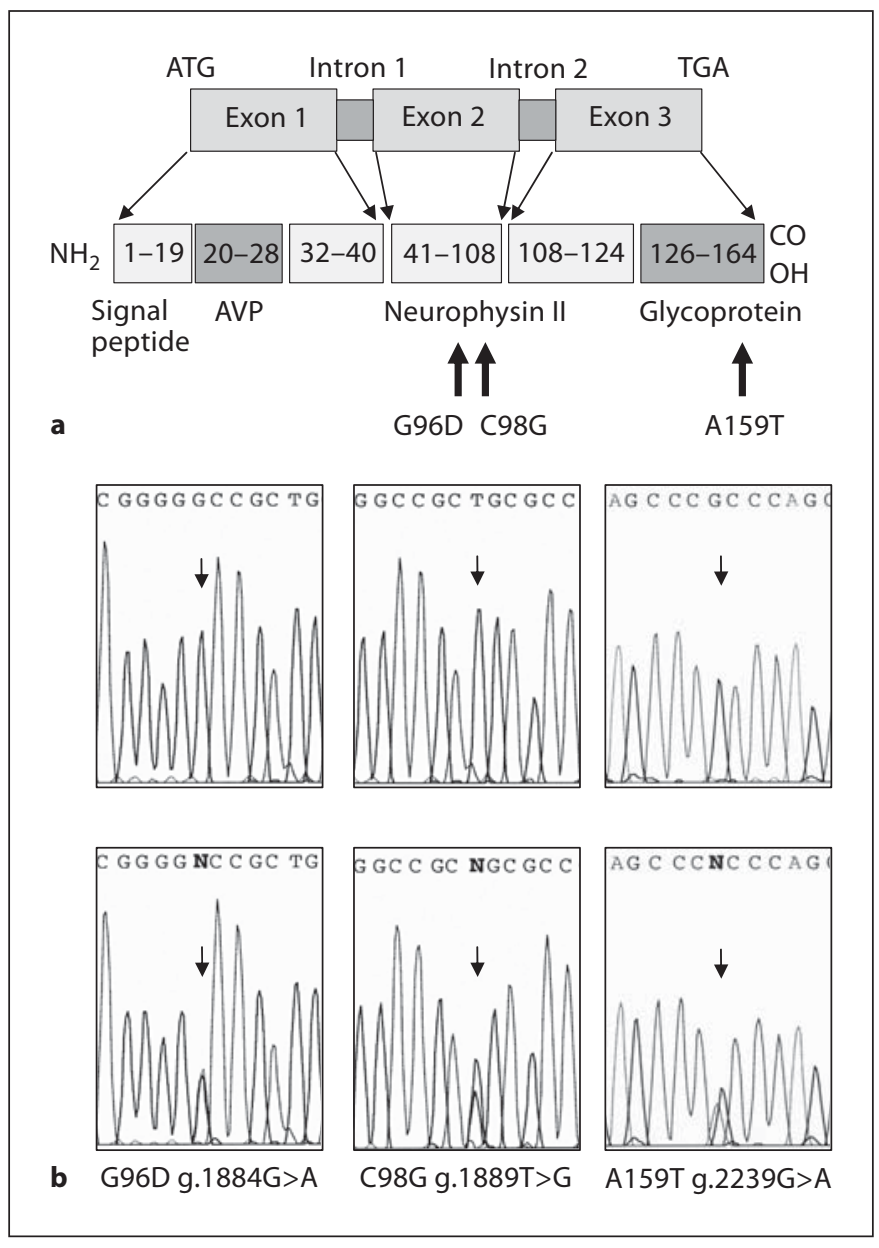

Fig. 1. a Structural organization of the AVP gene and the protein vasopressin precursor. b Sequence chromatograms demonstrating the heterozygous mutations g.1884G $>A$ (p.G96D) and g.2239G $>$ A (p.A159T) found in family 1 and g.1889T $>$ G (p.C98G) detected in family 2 (lower panel) and the corresponding normal sequence (upper panel).

gression to a severe disease after infancy with failure to elicit enough AVP to achieve urine concentration even under intense stimulation [1]. The arginine vasopressinneurophysin II (AVP) gene is located on human chromosome 20 (20p13) [3] and consists of three exons encoding the AVP preprohormone. The preprohormone comprises a signal peptide, the AVP nonapeptide, neurophysin II (NPII) and a C-terminal glycopeptide copeptin [1,4] (fig. 1a). After translocation of the newly synthesized preprohormone (or preproprotein) into the lumen of the endoplasmatic reticulum (ER) where the signal peptide is cleaved, the thereby originated AVP prohormone consisting of AVP, neurophysin II and glycopeptide folds into its final conformation and subsequently dimerizes. Neurophysin II is a cysteine-rich protein that contains seven disulfide bonds between its 14 cysteine residues. In normal precursor processing, one additional disulfide bond is formed within the AVP domain, and the copeptin (glycopeptide) moiety becomes glycosylated $[5,6]$. Concomitantly, the prohormone oligomerizes and is released into the trans Golgi network. The AVP peptide binds in a 'pocket' formed by neurophysin II which protects it from proteolytic degradation during the axonal transport of the secretory granule to the neurohypophysis where AVP is released as required $[1,7]$.

Many hypotheses for the pathogenesis of adFNDI have been postulated. Rutishauser et al. [8] and others [1,9] suggested that mutant precursor hormones are retained by the ER protein quality machinery resulting in cytotoxic accumulation and aggregation of protein in the neurons. A second hypothesis is that the mutant AVP prohormone is degraded by the cytosolic proteolytic system. This might be caused by deficient or insufficient function of mutant NPII molecules which are usually responsible for safe axonal transport and prevention of intracellular AVP proteolysis $[1,10,11]$.

Some of the over 30 mutations reported in the neurophysin II-coding region are thought to be responsible for protein misfolding by disrupting the intrachain disulfide bonds within neurophysin II which are responsible for the correct folding and stability of the AVP prohormone. Other mutations in the neurophysin II-coding region are located in the AVP-binding site [3, 12]. Several mutations affect the signal peptide and are proposed to disrupt signal protein processing [3, 13-15]. Four mutations are reported in the AVP-coding region itself $[9,11,16,17]$. One of these (p.Y21H) apparently disrupts AVP binding to a 'pocket' formed by several residues in the amino-terminal domain of neurophysin [9].

Here we screened two Polish families suffering from adFNDI for mutations in the $A V P$ gene. Using functional studies we demonstrate that the p.G96D and p.C98G mutations result in impaired cellular trafficking.

\section{Subjects and Methods}

\section{Subjects}

Eleven Polish individuals out of two families with a history of adFNDI have been studied. In family 1 , blood samples were obtained from 6 individuals suffering from adFNDI and from 1 family member presenting no clinical signs of adFNDI (fig. 2). In family 2, blood samples from 4 members were taken, 3 of them presenting with symptoms of adFNDI. Blood samples from all 
family members were obtained after written informed consent. Clinical symptoms and laboratory findings are displayed in table 1 . The study was approved by the local ethical committee, Medical University of Silesia, Poland.

\section{PCR and Sequencing}

Genomic DNA was purified from peripheral blood using the QIAamp DNA Mini Kit (Qiagen GmbH, Hilden, Germany). Two independent $20 \mu \mathrm{l}$ PCR reactions and three primer pairs in part previously published by Ito et al. $[18,19]$ (table 2 ) were used to amplify the entire AVP-NPII-coding region. Sequencing was performed using BigDye Terminator v1.1 Cycle Sequencing Kit (Applied Biosystems, Darmstadt, Germany) and an ABI 3100 Genetic Analyzer (Applied Biosystems). To exclude rare polymorphisms, sequencing of the coding regions of exons 2 and 3 was performed in 50 unrelated, healthy individuals for exon 2 and in 100 unrelated healthy individuals for exon 3.

\section{Construction of Expression Vectors}

A pBluescript SK+ plasmid containing a 592-bp human wildtype (WT) cDNA fragment encoding the entire human AVPNPII precursor protein was graciously provided by Prof. D. Richter, Institute for Cellular Biochemistry and Clinical Neurobiology, University of Hamburg (Germany). Complete AVP cDNA was excised from the pBluescript SK+ vector by cleavage with HindIII and $\mathrm{XbaI}$ (New England Biolabs, Frankfurt, Germany) and cloned into the multi cloning site of the pcDNA3 expression vector (Invitrogen, San Diego, Calif., USA).

Three different pcDNA3-AVP vectors were produced. The NPII moiety mutations p.G96D and p.C98G and the glycopeptide mutation p.A159T were introduced by site directed mutagenesis using oligonucleotides for a two-step PCR synthesis of mutant DNA according to Higuchi et al. [20]. The insert and ligation boundaries of all constructed vectors were sequenced to exclude PCR-derived nucleotide changes.

\section{Cell Culture and Transfection}

Mouse neuroblastoma Neuro2A cells (DSMZ, German Collection of Microorganisms and Cell Cultures, Braunschweig, Germany) were cultured in DMEM, supplemented with $10 \%$ heat-inactivated fetal calf serum (Gibco Life Technologies, Karlsruhe, Germany). The cells were maintained in a $5 \% \mathrm{CO}_{2}$ atmosphere at $37^{\circ} \mathrm{C}$.

Transfections with pcDNA3-AVP-WT, -G96D, -A159T, and -C98G were performed using Fugene 6 (Roche Applied Science, Mannheim, Germany) according to the manufacturer's instructions. Lines stably expressing the AVP-NPII cDNAs were selected using $0.4 \mathrm{mg} / \mathrm{ml}$ G418 (Geneticin, Gibco Invitrogen Corp., Karlsruhe, Germany) as previously described [17].

\section{Immunostaining and Microscopy}

For immunostaining and confocal laser scanning microscopy, stably transfected Neuro2A cells were grown on slides for $24 \mathrm{~h}$ in culture medium and an additional $24 \mathrm{~h}$ in serum-free culture medium. Cells were then fixed with $4 \%$ formaldehyde and immunostained. We used a primary goat anti-human NPII antibody (R\&D Systems, Abington, UK) and a secondary Alexa 546 donkey antigoat IgG antibody (Molecular Probes, Invitrogen GmbH, Karlsruhe, Germany). Images were acquired using a TCS SP2 confocal laser microscope (Leica, Mannheim, Germany).

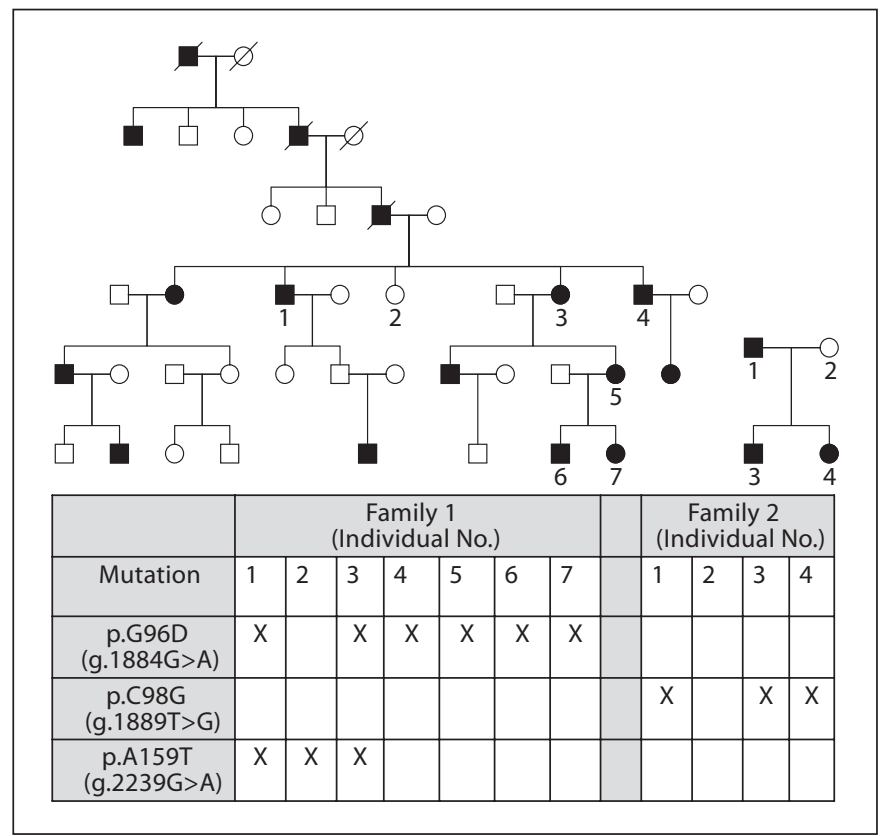

Fig. 2. Pedigrees of families 1 and 2 . The individuals marked with numbers are those who were available for mutation screening of the $A V P$ gene. Black and white symbols represent clinically affected and unaffected individuals, respectively. In the table the occurrence of the disease-causing mutations g.1884G $>$ A (p.G96D) and g.1889T $>$ G (p.C98G) and the rare polymorphism g.2239G >A (p.A159T) detected in different individuals of families 1 and 2 are summarized.

\section{AVP Radioimmunoassay (RIA)}

For measurement of AVP levels from cell culture supernatants, a double antibody RIA according to a modified method of Glick and Kagan [21] was performed using vasopressin direct RIA (Bühlmann Laboratories AG, Schönenbuch, Switzerland). Neuro2A cells stably expressing AVP-NPII were seeded in 6-well plates overnight and cultured for $24 \mathrm{~h}$ in serum-free culture medium before collecting supernatants for AVP RIA. The cells of each well were harvested, lysed and protein levels were determined using DC Protein Assay (BioRad, Hercules, Calif., USA). AVP values were detected as $\mathrm{pg} / \mathrm{ml}$ and converted in pg per milligram of total cell lysate protein per well.

\section{Magnetic Resonance Imaging (MRI)}

One affected member of family 1 (No. 6, fig. 2) was studied on a 0.5 T MRI (Philips, Gyroscan) and 2 affected members of family 2 (No. 3 \& 4, fig. 2 ) were studied on a 1.5 T MRI (Siemens, Symphony). High-resolution images were obtained with $230 \times$ $230 \mathrm{~mm}$ field of view, $3 \mathrm{~mm}$ slice thickness. Sagittal and coronal series were acquired pre- and postcontrast (gadolinium-DTPA) and without fat suppression. $\mathrm{T}_{1}$-weighted spin-echo sequences were used for detection of 'bright spots' representing neurovesicles in the axons of AVP-secreting neurons in the posterior pituitary gland [8]. 
Table 1. Clinical symptoms and laboratory findings of investigated individuals including urine and serum osmolality, and serum electrolytes

\begin{tabular}{|c|c|c|c|c|c|c|c|c|}
\hline $\begin{array}{l}\text { Individual } \\
\text { No. }\end{array}$ & $\begin{array}{l}\text { Serum } \\
\text { osmolality } \\
\text { mosm/l }\end{array}$ & $\begin{array}{l}\text { Urine } \\
\text { osmolality } \\
\text { mosm/l }\end{array}$ & $\begin{array}{l}\text { DDAVP } \\
\text { therapy } \\
\text { (Minirin) }\end{array}$ & $\begin{array}{l}\text { Serum } \\
\text { sodium } \\
\mathrm{mmol} / \mathrm{l}\end{array}$ & $\begin{array}{l}\text { Serum } \\
\text { potassium } \\
\mathrm{mmol} / \mathrm{l}\end{array}$ & $\begin{array}{l}\text { Serum } \\
\mathrm{ADH} \\
\mathrm{pg} / \mathrm{ml}\end{array}$ & $\begin{array}{l}\text { Fluid intake } \\
\text { per } 24 \mathrm{~h}, 1\end{array}$ & $\begin{array}{l}\text { Nycturia } \\
\text { times per } \\
\text { night }\end{array}$ \\
\hline \multicolumn{9}{|l|}{ Family 1} \\
\hline 1 & n.d. & n.d. & no & 143 & 4.2 & n.d. & 4.5 & 4 \\
\hline 2 & n.d. & n.d. & no & 147 & 4.8 & n.d. & 2 & 0 \\
\hline 3 & n.d. & n.d. & no & 146 & 4.4 & n.d. & 15 & 4 \\
\hline 4 & n.d. & n.d. & no & 143 & 4.0 & n.d. & 14 & $4-5$ \\
\hline 5 & 288 & 203 & no & 141 & 4.0 & 2.15 & 12 & 6 \\
\hline 6 & 290 & 230 & yes & 139 & 4.5 & 1.31 & 5.25 & 4 \\
\hline 7 & 293 & 277 & no & 140 & 3.9 & 4.12 & 1.1 & $0-1$ \\
\hline \multicolumn{9}{|l|}{ Family 2} \\
\hline 1 & 291 & 209 & $4 \times 0.1 \mathrm{mg} /$ day & 139.1 & 4.15 & 1.38 & 12 & 4 \\
\hline 2 & 292 & 536 & no & 138 & 4.25 & 3.99 & 1 & 0 \\
\hline 3 & 296 & 213 & $4 \times 0.1 \mathrm{mg} /$ day & 140.7 & 5.08 & 0.46 & 15 & 9 \\
\hline 4 & 323 & 198 & $2 \times 0.1 \mathrm{mg} /$ day & 140.7 & 5.33 & 0.73 & $8-9$ & $3-4$ \\
\hline
\end{tabular}

For all individuals, fluid intake and nycturia as clinical symptoms in adFNDI (autosomal dominant familial neurohypophyseal diabetes insipidus) are displayed.

DDAVP = Desmopressin; ADH = antidiuretic hormone, synonym to vasopressin; n.d. = no data available secondary to lacking compliance of the family members. AVP radioimmunoassays have been performed following standard protocols published elsewhere [21] (normal range: $0.60-6.70 \mathrm{pg} / \mathrm{ml}$ ).

Table 2. Primers used for DNA amplification by PCR

\begin{tabular}{lll}
\hline & Direction & Primer \\
\hline Exon 1 & Forward & 5'-TGGCGGCCGCGTCTCGCCTCCACGGGAACA-3' \\
& Reverse & $5^{\prime}$-GCTATGGCTGCCCTGAGATGGCCCACAGTG-3' \\
\hline Exon 2 & Forward & $5^{\prime}$-TCGCTGCGTTCCCCTCCAACCCCTCGACTC-3' \\
& Reverse & $5^{\prime}$-GCCCCCCCCCAGGCCCGCCCCCGCCGCGCA-3' \\
\hline Exon 3 & Forward & $5^{\prime}$-CCCAGGGCGCCCGTGCTCACACGTCCTCCCG-3' \\
& Reverse & $5^{\prime}$-CCTCTCTCCCCTTCCCTCTTCCCGCCAGAG-3' \\
\hline
\end{tabular}

Primers for exons 1 and 3 have been previously reported [17, 18]. The primers for exon 2 have been slightly modified to improve sequencing results.

\section{Results}

\section{Molecular Analyses}

The entire $A V P$ gene has been investigated in all numbered family members (fig. 2). In family 1 all affected individuals showed a $\mathrm{G}>\mathrm{A}$ transition in exon 2 at nucleotide position 1884 (g.1884G>A) (fig. 1) which was not present in the healthy family member (fig. 2). This mutation maps to $\mathrm{cDNA}$ position 287 (c.287G $>$ A) and predicts a replace- ment of glycine by aspartic acid in position 96 of the amino acid sequence of the prepro-AVP-NPII-precursor-protein (p.G96D) which is equivalent to amino acid 65 of NPII (NP65). An additional missense mutation in exon 3 at nucleotide position 2239 (g.2239G $>$ A) (fig. 1) encoding for the glycopeptide has been identified in 3 of the family members with or without symptoms of adFNDI (fig. 2). This mutation concerns cDNA position 475 (c.475G $>$ A) and predicts a replacement of alanine by threonine in 
Fig. 3. Cellular localization of NPII-reactive proteins in stably transfected Neuro2A cells expressing WT AVP (a) as well as the AVP-p.G96D (b), the AVP-p.A159T (c), and the AVP-p.C98G mutant proteins (d). Expressed neurophysin II-reactive proteins were detected by incubation with a goat anti-human neurophysin II antibody and an Alexa 546 donkey anti-goat IgG antibody. a, c NPII in the cytoplasm of the cellular body and in the tips of cellular processes where secretory granules are located. To some extent NPII is localized in the dendritic part of the axons on its way to the secretory granules at the tip of the axon marked with white arrows $(\rightarrow)$. b, d NPII in the cytoplasm of the cellular body. To some extent NPII is localized in the dendritic part of the axons $(\downarrow)$. There is no accumulation of NPII in the tip of the axons, and NPII seems not to be stored in secretory granules.
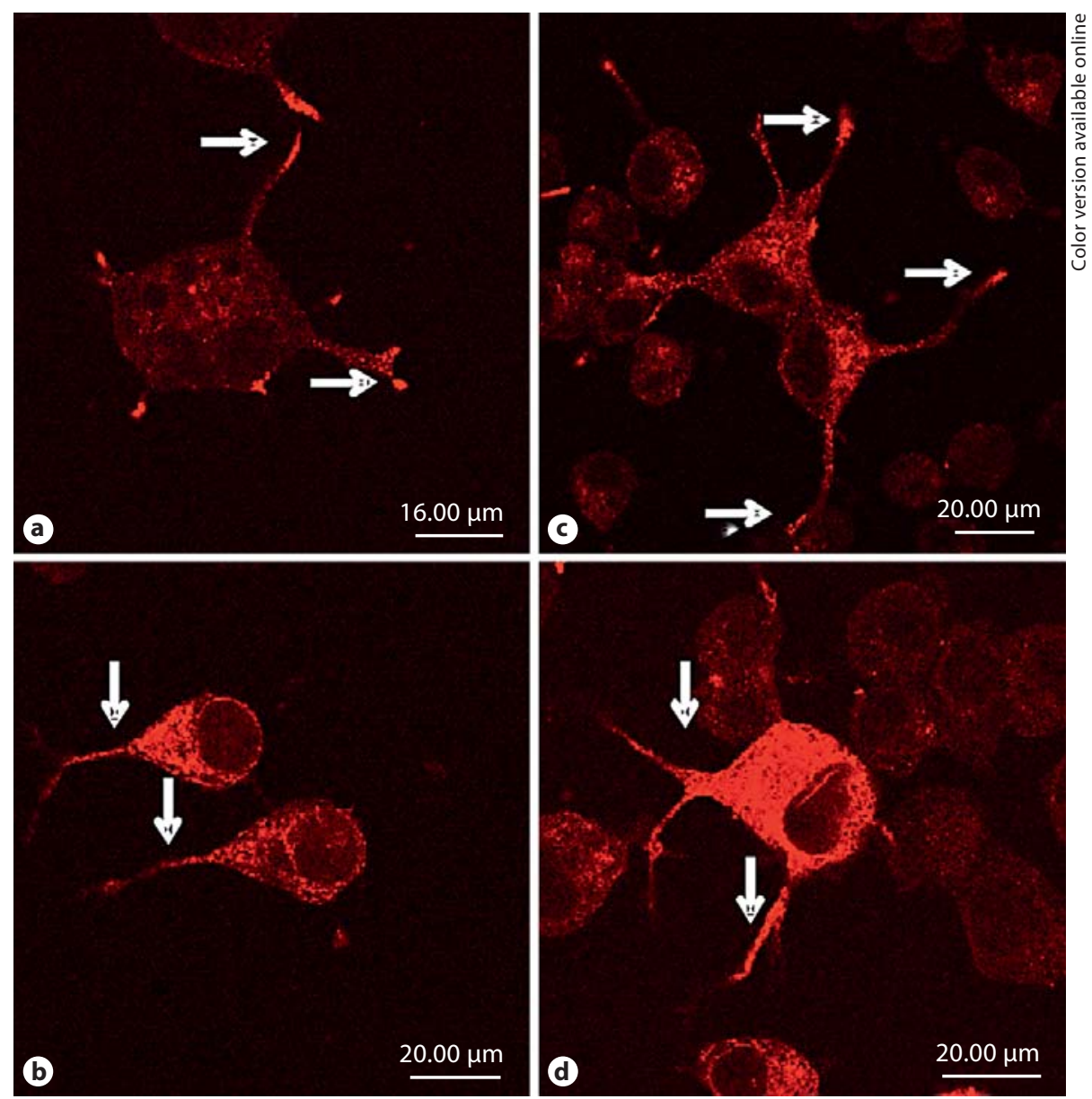

amino acid position 159 of the preproprotein (p.A159T) that is equivalent to amino acid 34 of copeptin (CP34). In all affected members of family 2 we identified a transversion $\mathrm{T}>\mathrm{G}$ in exon 2 at nucleotide position 1889 (g.1889 $\mathrm{T}>\mathrm{G}$ ) which concerns cDNA position 292 (c.292T $>\mathrm{G}$ ) and predicts a replacement of cysteine by glycine in amino acid position 98 of the preproprotein (p.C98G) which is equivalent to amino acid 67 of NPII (NP67) (fig. 1, 2).

Sequencing of exons 2 and 3 of the AVP gene of 50 (exon 2) and 100 (exon 3) unrelated healthy individuals showed no polymorphisms in the nucleotide positions mentioned above.

\section{Functional Studies}

Immunostaining: Confocal Laser Scanning Microscopic Analysis of the Intracellular Localization of AntiNeurophysin II-Reactive Proteins. In order to compare intracellular trafficking of WT and mutant AVP NPII prohormones and their processed products, the intra- cellular localization of neurophysin II-reactive proteins were determined in stably transfected Neuro2A cells (fig. 3).

In cells transfected with pcDNA3-AVP-WT or pcDNA3-AVP-A159T, NPII was localized in the dendritic parts of the axons and in vesicular structures in the tips of the cellular processes which appear to colocalize with secretory granules.

In cells transfected with pcDNA3-AVP-G96D or pcDNA3-AVP-C98G, neurophysin II-reactive proteins retained in the cytoplasmatic areas of the cellular bodies and to some extent in the dendritic parts of the neuronal cells. No activity has been detected in the tips of the cellular processes where the secretory granules are expected to be located.

AVP Radioimmunoassay. In order to investigate whether mutations in the patients of families 1 and 2 are crucial for vasopressin expression and excretion, we examined AVP secretion of Neuro2A cells stably trans- 


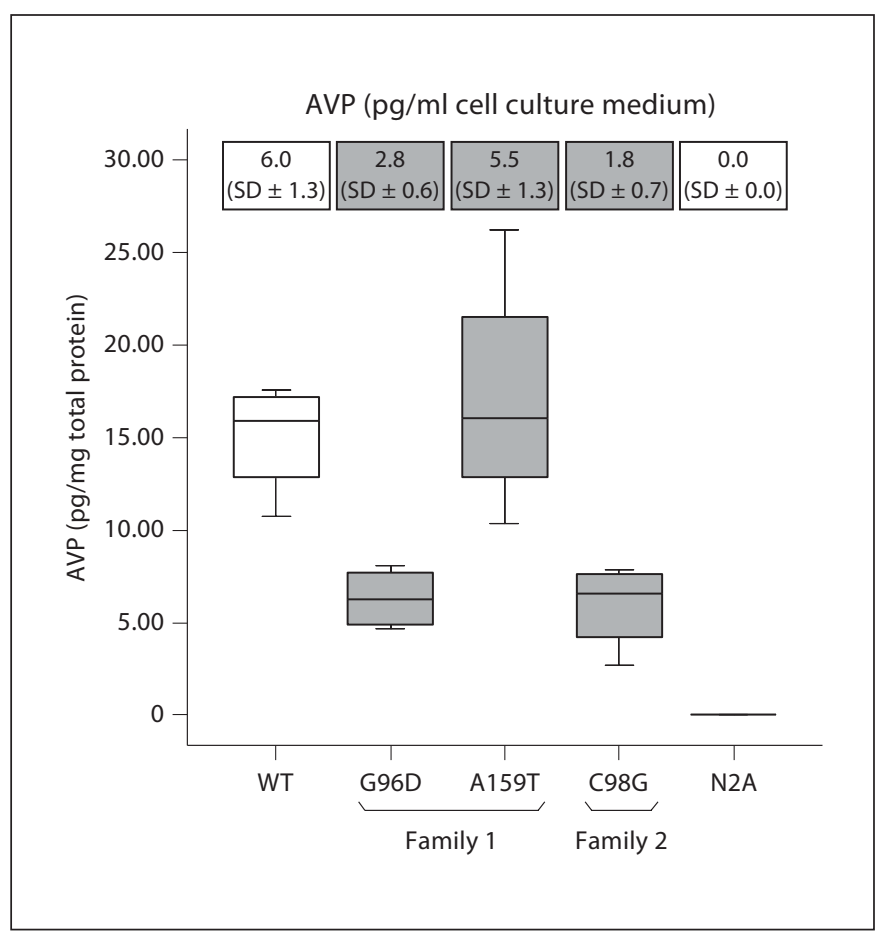

Fig. 4. Effect of the point mutations p.G96D (g.1884G>A), p.C98G (g.1889T $>$ G) and p.A159T (g.2239G $>$ A) on vasopressin secretion of transfected cells into the cell culture medium. Absolute AVP values are displayed in boxes including standard deviations (SD). Relative values normalized to the cellular protein content of each well (in pg AVP per mg protein) are illustrated as boxplots containing the median, upper and lower quantiles and upper and lower whisker intervals.

fected with WT and mutant vasopressin cDNAs. AVP levels in the supernatant culture medium were detected by RIA and referred to the protein content of each well (fig. 4).

The two missense mutations, p.G96D and p.C98G, expressed by Neuro2A cells result in significantly lower vasopressin levels in the supernatant cell medium than cells transfected with WT cDNA. The point mutation p.A159T which has been detected in some affected and unaffected individuals of family 1 does not seem to have an effect on vasopressin secretion out of the cell into the culture medium. Neuro2A cells have previously been reported secreting no vasopressin to the culture medium $[6,7,16]$.

Magnetic Resonance Imaging. The characteristic highintensity signal known as 'bright spot' in $\mathrm{T}_{1}$-weighted images without fat suppression of the pituitary was absent in all examined and affected individuals of both families.
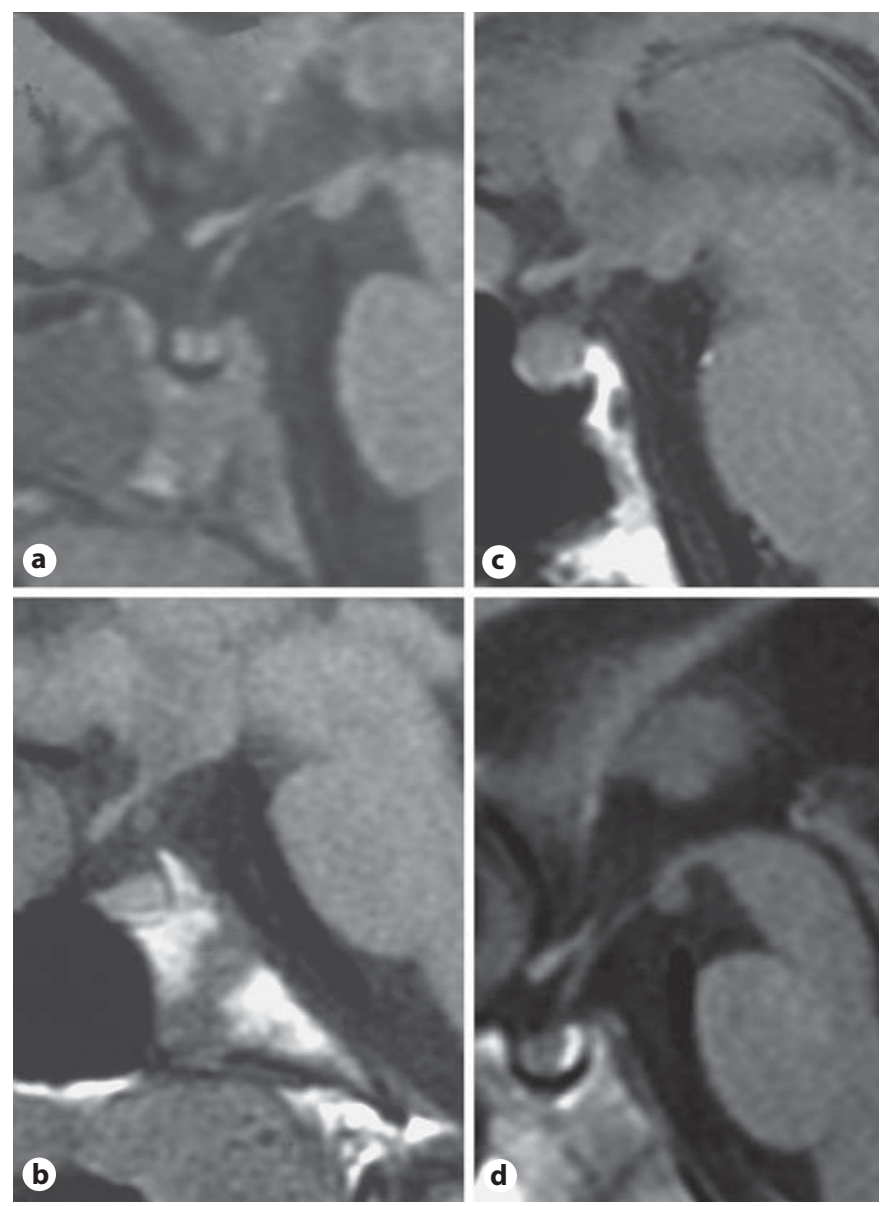

Fig. 5. MRI of affected family members in comparison to a nonrelated control: (a) family 1, individual No. 6, (b) family 2, individual No. 3, (c) family 2 , individual No. 4 , and (d) control individual. In the pre-contrast $\mathrm{T}_{1}$-weighted sequences, no typical high-intensity signal in projection to the posterior pituitary gland could be displayed in all 3 patients. The hypophysis is projected in orthotopic location. An ectopic pituitary gland was not seen. Note the normal high-intensity signal of the posterior lobe of the pituitary gland in an unaffected control individual (d).

In figure 5, magnetic resonance images of the pituitary gland of individual No. 6 (family 1) and individuals No. $3 \& 4$ (family 2) are displayed in comparison to a non-related normal control.

\section{Discussion}

Two heterozygous mutations in exon 2 of the AVP gene encoding for neurophysin II (p.G96D and p.C98G) and one previously unidentified missense mutation in 
exon 3 encoding for the glycopeptide (p.A159T) have been identified in two Polish kindreds suffering from adFNDI. Whereas the two mutations in exon 2 have been previously reported in other adFNDI patients $[7$, 22], the p.A159T mutation is novel but does not cosegregate with the disease in family 1 . Individuals carrying both mutations p.G96D and p.A159T show symptoms of adFNDI (individuals 1 and 3, fig. 2) but not the individual carrying the nucleotide substitution p.A159T alone (individual 2, fig. 2). Therefore, p.A159T seems to be a sequence variant and not a disease-causing mutation.

Using transfection and immunocytochemistry assays and measuring AVP secretion of transfected Neuro2A cells, we show for the first time that the mutations p.G96D and p.C98G cause a failure in transport of the mutant AVP-neurophysin II proteins to the tips of the cellular processes where the secretory granules are located. This results consecutively in a marked reduction of AVP secretion. The location of two mutations in exon 2, where a number of additional mutations have been reported, suggests this region as a hot spot for mutations and being of importance for appropriate secretion of AVP.

In mutation-positive cells, immunocytochemistry unveiled NPII-reactive protein accumulation in the perinuclear cytoplasm where the ER is located. Si-Hoe et al. [23] assumed that misfolded proteins might be trapped in the ER which causes proteolytic degradation of the deranged ER with consecutive progressive cell loss associated with increasing clinical symptoms in the affected individuals. The presence of some NPII-reactive protein in the axonal part of neurons of mutation-positive cells carrying p.G96D or p.C98G mutations could be due to an impaired axonal transport of abnormally configured prohormones which passed through the ER and the Golgi control machinery. During axonal transport these abnormal proteins may then get degraded by proteolytic enzymes [1]. On the other hand, the presence of NP II-reactive protein in the axonal part of these cells might also be due to its intraendoplasmatic location as ER can be located in the cellular processes of Neuro2A cells in which stained proteins might be trapped in this case. Based on our findings it cannot clearly be distinguished between these two possibilities.

The presence of minimal levels of AVP in the cell culture supernatants of cells transfected with the p.G96D and p.C98G mutant AVP can be either due to a remaining activity of these cells to secrete AVP into the medium, to cell degradation or to subcellular mRNA trafficking and local translation in dendrites as recently reported by Mohr and Richter [24].

For the g.2239G $>$ A (p.A159T) sequence variant in exon 3, no functional relevance could be observed when compared to cells transfected with WT AVP. This result is in accordance with the lack of cosegregation of this mutation in family 1 and the lack of clinical symptoms in the individual carrying the g.2239G $>$ A (p.A159T) sequence variant alone. On the other hand, it was not detected in 100 alleles of unrelated healthy individuals. We therefore conclude that the g.2239G $>$ A (p.A159T) sequence variant is a rare polymorphism and exclude a pathogenetic relevance.

Mutations in the NPII-coding region of the AVP gene seem to cause an early disease onset [2, 12]. Nevertheless, Repaske et al. [15] reported of a pedigree carrying signal peptide mutations exhibiting a wide range in the age of onset. In family 1 there is lacking clinical information secondary to a persistent non-compliance. Serum AVP levels are in the lower range of normal in 2 of the 3 examined and affected family members. Individual No. 7 still has normal serum AVP levels but pathologic urine parameters (reduced osmolality) and a positive personal history with polydipsia and polyuria since 18 months of age. This might be due to persisting but diminishing neurosecretory function of magnocellular neurons in the first years of life as already postulated by others, with progression to cytotoxic accumulation of mutant protein in the cytoplasmatic region of neurons $[1,5,8,23]$. Comparing the limited clinical data of patients in family 1 carrying the sequence variant g.2239G $>$ A (p.A159T) in addition to the p.G96D point mutation, there seems to be no aggravating effect.

Consistent with the results of Rutishauser et al. [8] and others [25-27], all 3 investigated patients of the two families did not show the 'bright spot' in $\mathrm{T}_{1}$-weighted pituitary images. Signal intensity is discussed to correlate closely with posterior lobe function as it is suspected to result from neurovesicles in axon endings of AVP-producing neurons $[8,28]$. The absence of a 'bright spot' in the posterior pituitary lobe could therefore be the result of neurotoxic accumulation of precursor proteins $[1,5,8$, 23] leading to consecutive cell death [19].

In family 1, individual No. 7 has been identified as being affected by genomic sequencing. At this time the child was 12 months old and asymptomatic. It was only at the age of 18 months that this child developed symptoms typical for adFNDI. This demonstrates the possibility of a preclinical diagnosis of adFNDI by genomic sequencing aiming at an early diagnosis and treatment of 
affected infants. However, some individuals might be missed because of recently reported mutation-negative forms of adFNDI [29] and splice mutations in the intronic regions of the $A V P$ gene [30].

\section{Acknowledgments}

The authors thank Heike Petzold and Petra Mitzscherling for their skilled laboratory assistance. We are grateful to Dietmar Richter, Institute for Cellular Biochemistry and Clinical Neurobiology, University of Hamburg, Germany, for providing the wild-type pBluescript-AVP vector. We also thank Sybille Bergmann and Mario Menschikowski, Laboratory of Clinical Chemistry and Laboratory Medicine, Technical University Dresden, Germany, for performing the AVP-RIAs.

\section{References}

1 Christensen JH, Siggaard C, Rittig S: Autosomal dominant familial neurohypophyseal diabetes insipidus. APMIS 2003; 109(suppl):92-95.

2 Grant FD, Ahmadi A, Hosley CM, Majzoub JA: Two novel mutations of the vasopressin gene associated with familial diabetes insipidus and identification of an asymptomatic carrier infant. J Clin Endocrinol Metab 1998; 83:3958-3964.

3 Santiprabhob J, Browning J, Repaske DR: A missense mutation encoding Cys73Phe in neurophysin II is associated with autosomal dominant neurohypophyseal diabetes insipidus. Mol Genet Metab 2002;77:112-118.

4 Sausville E, Carney D, Battey J: The human vasopressin gene is linked to the oxytocin gene and is selectively expressed in a cultured lung cancer cell line. J Biol Chem 1985; 260:10236-10241.

5 Ito M, Jameson JL, Ito M: Molecular basis of autosomal dominant neurohypophyseal diabetes insipidus. Cellular toxicity caused by the accumulation of mutant vasopressin precursors within the endoplasmic reticulum. J Clin Invest 1997;99:1897-1905.

6 Siggaard C, Rittig S, Corydon TJ, Andreasen $\mathrm{PH}$, Jensen TG, Andresen BS, Robertson BL, Gregersen N, Bolund L, Pedersen EB: Clinical and molecular evidence of abnormal processing and trafficking of the vasopressin preprohormone in a large kindred with familial neurohypophyseal diabetes insipidus due to a signal peptide mutation. J Clin Endocrinol Metab 1999;84:2933-2941.

7 Christensen JH, Siggaard C, Corydon TJ, de Sanctis L, Kovacs L, Robertson GL, Gregersen N, Rittig S: Six novel mutations in the arginine vasopressin gene in 15 kindreds with autosomal dominant familial neurohypophyseal diabetes insipidus give further insight into the pathogenesis. Eur J Hum Genet $2004 ; 12: 44-45$.
8 Rutishauser J, Boni-Schnetzler M, Böni J, Wichmann W, Huisman T, Valloton MB, Froesch ER: A novel point mutation in the translation initiation codon of the pre-provasopressin-neurophysin II gene: cosegregation with morphological abnormalities and clinical symptoms in autosomal dominant neurohypophyseal diabetes insipidus. J Clin Endocrinol Metab 1996;81:192-198.

9 Rittig S, Siggaard C, Ozata M, Yetkin I, Gregersen N, Pedersen EB, Robertson GL: Autosomal dominant neurohypophyseal diabetes insipidus due to substitution of histidine for tyrosine-2 in the vasopressin moiety of the hormone precursor. J Clin Endocrinol Metab 2002;87:3351-3355.

10 Davies J, Murphy D: Autophagy in hypothalamic neurones of rats expressing a familial neurohypophysial diabetes insipidus transgene. J Neuroendocrinol 2002;14:629-637.

11 Willcutts MD, Felner E, White PC: Autosomal recessive familial neurohypophyseal diabetes insipidus with continued secretion of mutant weakly active vasopressin. Hum Mol Genet 1999;8:1303-1307.

12 Gagliardi PC, Bernasconi S, Repaske DR Autosomal dominant neurohypophyseal diabetes insipidus associated with a missense mutation encoding Gly23 $\rightarrow$ Val in neurophysin II. J Clin Endocrinol Metab 1997;82: 3643-3646.

13 Calvo B, Bilbao JR, Rodriguez A, Castano L: Molecular analysis in familial neurohypophyseal diabetes insipidus: early diagnosis of an asymptomatic carrier. J Clin Endocrinol Metab 1999;84:3351-3354.

14 Heppner C, Kotzka J, Bullmann C, Krone W, Müller-Wieland D: Identification of mutations of the arginine vasopressin-neurophysin II gene in two kindreds with familial central diabetes insipidus. J Clin Endocrinol Metab 1998;83:693-696.

15 Repaske DR, Medlej R, Gültekin EK, Krishnamani MRS, Halaby G, Findling JW, Phillips JA III: Heterogeneity in clinical manifestation of autosomal dominant neurohypophyseal diabetes insipidus caused by a mutation encoding Ala- $1 \rightarrow \mathrm{Val}$ in the signal peptide of the arginine vasopressin/neurophysin II/copeptin precursor. J Clin Endocrinol Metab 1997;82:51-56.
16 Wahlstrom JT, Fowler MJ, Nicholson WE, Kovacs WJ: A novel mutation in the preprovasopressin gene identified in a kindred with autosomal dominant neurohypophyseal diabetes insipidus. J Clin Endocrinol Metab 2004;89:1963-1968.

17 Koboyashi H, Fujisawa I, Ikeda K, Son C, Iwakura T, Yoshimoto A, Kasahara M, Ishihara T, Ogawa Y: A novel heterozygous missense mutation in the vasopressin moiety is identified in a Japanese person with neurohypophyseal diabetes insipidus. J Endocrinol Invest 2006;29:252-256.

18 Ito M, Mori Y, Oiso Y, Saito H: A single base substitution in the coding region for neurophysin II associated with familial central diabetes insipidus. J Clin Invest 1991;87:725728.

19 Ito M, Yu RN, Jameson JL, Ito M: Mutant vasopressin precursors that cause autosomal dominant neurohypophyseal diabetes insipidus retain dimerization and impair the secretion of wild-type proteins. J Biol Chem 1999;274:9029-9037.

20 Higuchi R, Krummel B, Saiki RK: A general method of in vitro preparation and specific mutagenesis of DNA fragments: study of protein and DNA interactions. Nucleic Acids Res 1988;16:7351-7367.

21 Glick SM, Kagan A: Radioimmunoassay of arginine vasopressin; in Jaffe BM, Behrmann HR (eds): Methods of Hormone Radioimmunoassays. New York, Academic Press, 1979, pp 341-351

22 DiMeglio LA, Gagliardi PC, Browning JE, Quingley CA, Repaske DR: A missense mutation encoding Cys(67) $\rightarrow$ Gly in neurophysin II is associated with early onset autosomal dominant neurohypophyseal diabetes insipidus. Mol Genet Metab 2001;72:39-44.

23 Si-Hoe SL, De Bree F, Nijenhuis M, Davies JE, Howell LMC, Tinley H, Waller SJ, Zeng Q, Zalm R, Sonnemans M, van Leeuwen FW, Burbach JPH, Murphy D: Endoplasmic reticulum derangement in hypothalamic neurons of rats expressing a familial neurohypophyseal diabetes insipidus mutant vasopressin transgene. FASEB J 2000;14: $1680-1684$ 
24 Mohr E, Richter D: Subcellular vasopressin mRNA trafficking and local translation in dendrites. J Neuroendocrinol 2004;16:333339.

25 Ozata M, Tayfun C, Kurtaran K, Yetkin I, Beyhan Z, Corakci A, Cağlayan S, Alemdaroglu A, Gündogan MA: Magnetic resonance imaging of posterior pituitary for evaluation of the neurohypophyseal function in idiopathic and autosomal dominant neurohypophyseal diabetes insipidus. Eur Radiol 1997;7:1098-1102.
26 Flück CE, Deladoëy J, Nayak S, Zeller O, Kopp P, Mullis PE: Autosomal dominant neurohypophyseal diabetes insipidus in a Swiss family, caused by a novel mutation (C59D/A60W) in the neurophysin moiety of prepro-vasopressin-neurophysin II (AVPNP II). Eur J Endocrinol 2001;145:439-444.

27 Maghnie M, Villa A, Arico M, Larizza D, Pezzotta S, Beluffi G, Genovese E, Severi F: Correlation between magnetic resonance imaging of posterior pituitary and neurohypophyseal function in children with diabetes insipidus. J Clin Endocrinol Metab 1992;74: 795-800.

28 Kucharczyk W, Lenkinski RE, Kucharczyk J, Henkelman RM: The effect of phospholipid vesicles on the NMR relaxation of water: an explanation for the MR appearance of the neurohypophysis? Am J Neuroradiol 1990; 11:693-700.
29 Ye L, Li X, Chen Y, Sun H, Wang W, Su T, Jiang L, Cui B, Ning G: Autosomal dominant neurohypophyseal diabetes insipidus with linkage to chromosome 20p13 but without mutations in the AVP-NPII gene. J Clin Endocrinol Metab 2005;90:4388-4393.

30 Tae HJ, Baek KH, Shim SM, Yoo SJ, Kang MI, Cha BY, Lee KY, Son HY, Kang SK: A novel splice site mutation of the arginine vasopressin-neurophysin II gene identified in a kindred with autosomal dominant familial neurohypophyseal diabetes insipidus. Mol Genet Metab 2005;86:307-313. 